\title{
Herbivory on the pedunculate oak along urbanization range in Europe: effects of local forest cover and insect feeding guild
}

Elena Valdés-Correcher ${ }^{1}$, Anna Popova ${ }^{2}$, Andrea Galmán ${ }^{3}$, Andreas Prinzing $^{4}$, Andrey Selikhovkin $^{5}$, Andy Howe ${ }^{6}$, Anna Mrazova ${ }^{7}$, Anne-Maïmiti Dulaurent ${ }^{8}$, Arndt Hampe ${ }^{1}$, Ayco Tack ${ }^{9}$, Christophe Bouget ${ }^{10}$, Daniela Lupaștean ${ }^{11}$, Deborah Harvey ${ }^{12}$, Dmitry Musolin $^{5}$, Gabor Lövei ${ }^{13}$, Giada Centenaro ${ }^{9}$, Inge Halder ${ }^{1}$, Jonas Hagge ${ }^{14}$, Jovan Dobrosavljević $^{15}$, Juha-Matti Pitkänen ${ }^{16}$, Julia Koricheva ${ }^{12}$, Katerina Sam ${ }^{17}$, Luc Barbaro $^{18}$, Manuela Branco ${ }^{19}$, Marco Ferrante ${ }^{20}$, Maria Faticov ${ }^{9}$, Markéta Tahadlová ${ }^{21}$, Martin M. Gossner ${ }^{22}$, Maxime Cauchoix ${ }^{23}$, Michał Bogdziewicz ${ }^{24}$, Mihai-Leonard Duduman $^{11}$, Mikhail Kozlov ${ }^{25}$, Mona Bjoern ${ }^{6}$, Nikita Mamaev ${ }^{5}$, Pilar Fernandez-Conradi ${ }^{26}$, Rebecca Thomas ${ }^{27}$, Ross Wetherbee ${ }^{28}$, Samantha Green ${ }^{29}$, Slobodan Milanović ${ }^{15}$, Xoaquin Moreira $^{30}$, Yasmine Kadiri ${ }^{1}$, and Bastien Castagneyrol ${ }^{1}$

${ }^{1}$ INRAE Nouvelle-Aquitaine Bordeaux Centre

${ }^{2}$ Russian Academy of Sciences

${ }^{3}$ Martin Luther University Halle Wittenberg ${ }^{4} \mathrm{ECOBIO}$

${ }^{5}$ Saint Petersburg State Forest Technical University named after S M Kirov

${ }^{6}$ University of Copenhagen

${ }^{7}$ Biology Centre Czech Academy of Sciences

${ }^{8}$ UniLaSalle

${ }^{9}$ Stockholm University

${ }^{10}$ INRAE Val de Loire Site de Nogent-sur-Vernisson

${ }^{11}$ University of Suceava

${ }^{12}$ Royal Holloway University of London School of Biological Sciences

${ }^{13}$ Aarhus Universitet

${ }^{14}$ Northwest German Forest Research Institute

${ }^{15}$ University of Belgrade

${ }^{16}$ Natural Resources Institute Finland

${ }^{17}$ Institute of Entomology Biology Centre Czech Academy of Sciences

${ }^{18}$ DYNAFOR

${ }^{19}$ Universidade de Lisboa

${ }^{20}$ University of the Azores - Angra do Heroísmo Campus

${ }^{21}$ Biology Centre CAS

${ }^{22} \mathrm{WSL}$

${ }^{23} \mathrm{CNRS}$

${ }^{24}$ Adam Mickiewicz University

${ }^{25}$ University of Turku

${ }^{26} \mathrm{URFM}$

${ }^{27}$ University of Reading 


\author{
${ }^{28}$ Norwegian University of Life Sciences \\ ${ }^{29}$ Coventry University \\ ${ }^{30}$ Mision Biologica de Galicia
}

November 3, 2021

\begin{abstract}
Urbanization is recognized as an important driver of the diversity and abundance of tree associated insect herbivores, but its consequences for insect herbivory are controversial. A likely source of variability among studies is the insufficient consideration of intra-urban variability in forest cover. With the help of citizen scientists, we investigated the independent and interactive effect of urbanization and local canopy cover on insect herbivory in the pedunculate oak (Quercus robur) throughout most of its geographic range in Europe. The damage caused by chewing insect herbivores as well as the incidence of leaf-mining and gall-inducing herbivores consistently decreased with increasing urbanization around focal oaks. Herbivory by chewing herbivores increased with increasing forest cover, regardless of urbanization. In contrast, an increase in local canopy cover buffered the negative effect of urbanization on leaf-miners and strengthened its effect on gall-inducers. These results show the complexity of plant-herbivore interactions in urbanized areas, highlighting that the presence of local canopy cover within cities has the potential to attenuate or modify the effect of urbanization on biotic interactions.
\end{abstract}

Herbivory on the pedunculate oak along urbanization range in Europe: effects of local forest cover and insect feeding guild

\title{
Authors :
}

Elena Valdés Correcher ${ }^{1}$, Anna Popova ${ }^{2}$, Andrea Galmán ${ }^{3}, 4$, Andreas Prinzing ${ }^{5}$, Andrey V. Selikhovkin ${ }^{6}$, Andy G. Howe ${ }^{7,8}$, Anna Mrazova ${ }^{9},{ }^{10}$, Anne-Maïmiti Dulaurent ${ }^{11}$, Arndt Hampe ${ }^{1}$, Ayco Jerome Michel Tack ${ }^{12}$, Christophe Bouget ${ }^{13}$, Daniela Lupaștean ${ }^{14}$, Deborah Harvey ${ }^{15}$, Dmitry L. Musolin ${ }^{6}$, Gábor L. Lövei ${ }^{16}$, Giada Centenaro ${ }^{17}$, Inge Van Halder ${ }^{1}$, Jonas Hagge ${ }^{18,19}$, Jovan Dobrosavljević ${ }^{20}$, JuhaMatti Pitkänen ${ }^{21,22}$, Julia Koricheva ${ }^{15}$, Katerina $\mathrm{Sam}^{9}$, ${ }^{10}$, Luc Barbaro ${ }^{23}$, 24, Manuela Branco ${ }^{25}$, Marco Ferrante $^{16,26}$, Maria Faticov ${ }^{12}$, Markéta Tahadlová ${ }^{9,}{ }^{10}$, Martin Gossner ${ }^{27}$ 28, Maxime Cauchoix ${ }^{29}$, Michał Bogdziewicz $^{30}{ }^{31}$, Mihai-Leonard Duduman ${ }^{14}$, Mikhail V. Kozlov ${ }^{32}$, Mona C. Bjoern ${ }^{7}$, Nikita A. Mamaev ${ }^{6}$, Pilar Fernandez-Conradi ${ }^{33}$, Rebecca L. Thomas ${ }^{15}$, Ross Wetherbee $^{34}$, Samantha Green ${ }^{35}$, Slobodan Milanović $^{20,36}$, Xoaquín Moreira ${ }^{37}$, Yasmine Kadiri ${ }^{1}$ and Bastien Castagneyrol ${ }^{1}$.

\section{Affiliations :}

1 - Univ. Bordeaux, INRAE, BIOGECO, F-33612 Cestas, France

2 - A. N. Severtsov Institute of Ecology and Evolution, Russian Academy of Sciences, Leninsky 33, Moscow, 119071, Russia

3 - Institute of Biology/Geobotany and Botanical Garden, Martin Luther University Halle-Wittenberg, Germany

4 - German Centre for Integrative Biodiversity Research (iDiv) Halle-Jena-Leipzig, Germany

5 - Research Unit ECOBIO (Ecosystems, Biodiversity, Evolution), UMR 6553, University of Rennes/Centre National de la Recherche Scientifique, Campus Beaulieu, Bâtiment 14 A, 263 Av. du Général Leclerc, 35042 Rennes, France

6 - Department of Forest Protection, Wood Science and Game Management, Saint Petersburg State Forest Technical University, 194021 St. Petersburg, Russia

7 - Department of Geosciences and Natural Resource Management, University of Copenhagen, Rolighedsvej 23, 1958 Frederiksberg C, Denmark 
8 - Forest Industries Research Centre, University of the Sunshine Coast, Australia

9 - Biology Centre of Czech Academy of Sciences, Entomology Institute, Branisovska 31, Ceske Budejovice 370 05, Czech Republic

10 - Faculty of Science, University of South Bohemia, Branisovska 1760, Ceske Budejovice 370 05, Czech Republic

11 - UniLaSalle, AGHYLE, UP.2018.C101, SFR Condorcet FR CNRS 3417, FR-60026 Beauvais, France

12 - Department of Ecology, Environment and Plant Sciences, Stockholm University, 11418 Stockholm, Sweden

13 - Forest Ecosystems' Research Unit - Biodiversity team Domaine des Barres, INRAE, Nogent-surVernisson, France

14 - "Ștefan cel Mare" University of Suceava, Forestry Faculty, Applied Ecology Lab. University Str. 13, Suceava, Romania

15 - Dept of Biological Sciences, Royal Holloway, University of London, Egham Surrey, UK

16 - Department of Agroecology, Flakkebjerg Research Centre, Aarhus University, Slagelse, Denmark

17 - Department of Ecology, Environment and Plant Sciences, Stockholm University, Stockholm, SE

18 - Forest Nature Conservation, Northwest German Forest Research Institute, Prof.-Oelkers-Str. 6, 34346 Hann. Münden, Germany

19 - Forest Nature Conservation, Georg-August-University Gottingen, Busgenweg 3, 37077 Gottingen, Germany

20 - Department of Forest Protection, Faculty of Forestry, University of Belgrade, Kneza Višeslava 1, Belgrade, Serbia

21 - Forest Health and Biodiversity, Natural Resources Institute Finland (LUKE), Latokartanonkaari 9, 00790, Helsinki, Finland

22 - Spatial Foodweb Ecology Group, Department of Agricultural Sciences, University of Helsinki, Helsinki, Finland

23 - Dynafor, Univ. Toulouse, INRAE, Castanet-Tolosan, France

24 - CESCO, Museum national d'Histoire naturelle, CNRS, Sorbonne-Univ., Paris, France

25 - Centro de Estudos Florestais, Instituto Superior de Agronomia, Universidade de Lisboa, 1349-017 Lisboa, Portugal

26 - Azorean Biodiversity Group, cE3c - Centre for Ecology, Evolution and Environmental Changes, University of the Azores, Azores, Portugal

27 - Forest Entomology, Swiss Federal Research Institute WSL, Zürcherstrasse 111, CH-8903 Birmensdorf, Switzerland

28 - Department of Environmental Systems Science, Institute of Terrestrial Ecosystems, ETH Zürich, Zürich, Switzerland

29 - Station d'Ecologie Théorique et Expérimentale du CNRS, Moulis, France

30 - Department of Systematic Zoology, Faculty of Biology, Adam Mickiewicz University, Umutlowska 89, 61-614 Poznan, Poland

31 - Laboratoire EcoSystemes et Societes En Montagne, INRAE Univ Grenoble Alpes, 2 rue de la Papeterie, BP 76 F-38402 Saint-Martin-d'Heres cedex, France 
32 - Department of Biology, University of Turku, Turku 20014, Finland

33 - INRAE, UR629 Ecologie des Forets Mediterraneennes (URFM), Avignon 84914, France

34 - Faculty of Environmental Sciences and Natural Resource Management, Norwegian University of Life Sciences, Aas, Norway

35 - Centre for Agroecology, Water and Resilience, Coventry University, Ryton Organic Gardens, Coventry, CV8 3LG, UK

36 - Department of Forest Protection and Wildlife Management, Faculty of Forestry and Wood Technology, Mendel University in Brno, Zemedelska 3, 61300 Brno, Czech Republic

37 - Mision Biologica de Galicia (MBG-CSIC), Apdo. 28, 36080 Pontevedra, Galicia, Spain

Corresponding author : ELENA VALDES-CORRECHER, Univ. Bordeaux, INRAE, BIOGECO, F33612 Cestas, France.elena.valdes.correcher@gmail.com; Telephone number: +330769962199.

\section{Introduction}

Urbanization is one of the major drivers of global change (Lambert et al., 2015; Rossetti et al., 2017). It causes fragmentation, isolation and degradation of natural habitats (Pickett et al., 2001; Zipperer et al., 2000) in addition to creating warmer and drier conditions for both plants and animals (Chai et al., 2019; Taha, 1997; Wang et al., 2017). As a consequence, urbanization results in the simplification of ecological communities and the alteration of ecosystem processes such as biotic interactions (Bang and Faeth, 2011; Fenoglio et al., 2020; Magura et al., 2010; McDonnell and Hahs, 2015). Understanding how the nature and strength of species interactions change along urbanization gradients could help us to unravel the mechanisms driving changes in species distribution and composition, which remain insufficiently known (but see Kozlov, Lanta, Zverev, \& Zvereva, 2015; Moreira et al., 2019; Turrini, Sanders, \& Knop, 2016).

Plant-herbivore interactions play a pivotal role in ecosystems and consequently are one of the most studied biotic interactions (Jamieson et al., 2012; Stam et al., 2014). Analyses of insect herbivory patterns on woody and herbaceous plants along urban-rural gradients have received increasing attention in recent decades (Dreistadt et al., 1990; Kozlov et al., 2017; Moreira et al., 2019; Raupp et al., 2010). Several studies measured the response of a single herbivore species (Parsons and Frank, 2019; Turrini et al., 2016), that of different herbivore feeding guilds (Cuevas-Reyes et al., 2013; Kozlov et al., 2017; Moreira et al., 2019) or the diversity and abundance of herbivores (Fenoglio et al., 2020) in urban vs rural environments (but see Parsons \& Frank, 2019). Although there seems to be a general tendency towards reduced insect abundance and diversity in urban settings as compared to rural environments (Fenoglio et al., 2020), there is no consensus on whether insect herbivory is higher (Parsons and Frank, 2019; Turrini et al., 2016) or lower (Fenoglio et al., 2020; Kozlov et al., 2017; Moreira et al., 2019) in urban compared to rural habitats. Given these mixed findings, a better understanding of the underlying ecological factors driving urbanization effects on insect herbivory is needed.

Several factors may explain the inconsistent effects of urbanization on insect herbivory reported in the literature. First, insect herbivore species vary markedly in their susceptibility to changing abiotic conditions (Van Der Putten et al., 2010) and might therefore exhibit different patterns of abundance and damage on focal host plants in urbanvs rural areas (Kozlov et al., 2017; Moreira et al., 2019). In this sense, urban habitats are often associated with stressful climatic conditions (i.e., cities are warmer and drier than surrounding rural environments; Calfapietra, Penuelas, \& Niinemets, 2015; Dale \& Frank, 2014; Meineke \& Frank, 2018) where endophagous herbivore guilds, e.g., leaf-mining and leaf-galling herbivores, could outperform exophagous herbivores, e.g., leaf chewers (Koricheva et al., 1998). Second, cities differ greatly in the amount of vegetation they harbour. The local tree cover (i.e., both overall tree density and potential host tree abundance) is a strong driver of urban biodiversity and trophic interactions between trees, insect herbivores and their enemies (Herrmann et al., 2012; Long and Frank, 2020; Meyer et al., 2020; Stemmelen et al., 2020). More isolated trees frequently offer fewer resources to insect herbivores (Chavez-Pesqueira et al., 
2015), leading to a decrease in insect herbivory (Long and Frank, 2020). Isolated trees are also key (micro) habitats having a disproportionate importance for foraging predators, especially bats and birds (DeMars et al., 2010; Fischer et al., 2010; James Barth et al., 2015; Le Roux et al., 2018). At the same time, climatic conditions also vary with local tree cover resulting in high temperature and light intensity in more isolated trees, which may also influence insect herbivores (Dale and Frank, 2014; Shrewsbury and Raupp, 2000). In this way, the amount and distribution of green areas - and in particular that of trees - could interfere with the effect of urbanization on leaf herbivory. Thus, the relative importance of all these explanatory mechanisms needs to be confirmed along an urbanization gradient that ranges from 'green islands' with high tree density to almost fully paved areas with only a few isolated trees.

In this study, we investigated the independent and interactive effects of urbanization and local canopy cover on insect herbivory on the pedunculate oak (Quercus robur L., 1753) throughout most of its geographic range in Europe. To this end, we quantified herbivory as the proportion of leaf area consumed by chewing insect herbivores as well as the incidence of leaf-mining and gall-inducing herbivores in leaf samples collected by professional scientists and schoolchildren in European countries between 2018 and 2020. We specifically predicted that: (a) insect herbivory decreases with urbanization and increases with canopy cover; (b) the effects of urbanization and canopy cover on leaf herbivory vary among the herbivore guilds; and (c) urbanization and local canopy cover have an interactive effect on insect herbivory that vary among herbivore guilds. Overall, this work provides one of the most comprehensive studies yet, testing for effects of urbanization on plant-herbivore interactions and shedding light into potential mechanisms underlying such effects.

\section{Material and methods}

\section{Model system}

The pedunculate oak is one of the most common dominant deciduous tree species in European forests. It is also a popular ornamental tree in European urban areas (Eaton et al., 2016). Its distribution range spans from central Spain (23degN) to southern Fennoscandia (63degN) (Eaton et al., 2016). uercus robur is associated with a large community of generalist and specialist herbivorous insects belonging to different feeding guilds (chewers, skeletonizers, gall-inducers, leaf-miners, suckers and xylophagous) (Marković and Stojanović, 2011; Moreira et al., 2018; Southwood et al., 2005). These ecological characteristics make the pedunculate oak a suitable model species for measuring the effects of urbanization and forest cover on plant-herbivore interactions.

\section{Sampling network}

The present study is part of an ongoing citizen science project that involved so far a total of 93 participants, including 41 scientists and 52 partner schools from 17 European countries (Castagneyrol et al., 2019; ValdésCorrecher et al., 2021) covering most of the native geographical range of the pedunculate oak (Figure 1A ). We geolocalized and surveyed a total of 298 mature oak trees in forest and urban areas during 2018 ( $\mathrm{n}=$ 132), $2019(\mathrm{n}=56)$, and $2020(\mathrm{n}=113)$ (Figure 1$)$. 


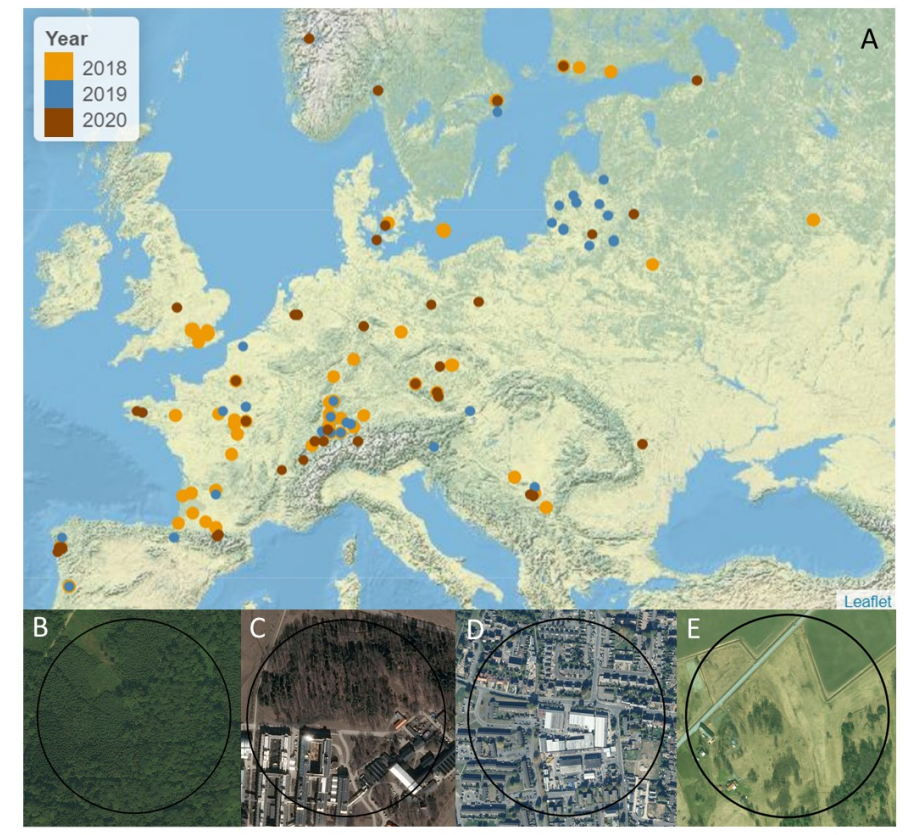

Figure 1. A map showing the location of trees sampled in 2018 (yellow circles), 2019 (blue circles) and 2020 (brown circles) by scientists and partner schools (A). Panels B-E show examples of $200 \mathrm{~m}$ radius buffers centered on sampled oak trees, with varying percentages of local canopy cover and urbanization. Panel B has $100 \%$ of local canopy cover and $0 \%$ of urbanization; panel C has $45 \%$ of local canopy cover and $40 \%$ of urbanization; panel D has $0 \%$ of local canopy cover and $100 \%$ of urbanization; and panel $\mathrm{E}$ has $30 \%$ of local canopy cover and $10 \%$ of urbanization. An interactive version of this map (A) is also included in the supplementary material as Figure A . The aerial images (B, C, D and E) are based on images from Bing maps, 2021.

\section{Leaf herbivory}

In early summer (about 10-12 weeks after oak budburst at each location), scientists and partner schools haphazardly selected four low hanging branches per tree facing opposite directions. They haphazardly collected 30 leaves per branch (total: 120 leaves per tree). Then, 60 leaves were drawn blindly to reduce unconscious bias in leaf sampling. Scientists oven-dried leaves for at least $48 \mathrm{~h}$ at $45^{\circ} \mathrm{C}$ right after collection $(\mathrm{n}=203$ oaks). Leaves collected by partner schools $(\mathrm{n}=98$ oaks $)$ were oven-dried when received by the project coordinators, to warrant optimal preservation prior to herbivory assessment.

Three response variables were used to characterize leaf herbivory (Valdés-Correcher et al., 2021): leaf damage (i.e., the percentage of leaf area removed by insect herbivores), leaf-miner incidence (i.e., the proportion of leaves with leaf-mines) and leaf-gall incidence (i.e., the proportion of leaves with galls). Herbivory was visually scored by assigning each to one of the following classes: 0, 0.1-5.0, 5.1-10.0, 10.1-15.0, 15.1-25.0, 25.1-50.0, $50.1-75.0$ or $>75 \%$, where the percentage represented the proportion of leaf surface removed by chewing herbivores, or mined by leaf-miners. We then used the midpoint of each class to average herbivory at the tree level (see Valdés-Correcher et al., 2021 for details). We did not assess damage caused by sucking insects because punctures vary widely among species and for some species are not very visible (Schaefer and Panizzi, 2000).

\section{Landscape characteristics and climatic data}

We defined the degree of urbanization around focal trees as the percentage of impervious surface (including roads and buildings) in a buffer with a radius of $200 \mathrm{~m}$ centered on the focal oaks based on oak coordinates 
as retrieved from Google Maps by project partners (Meyer et al., 2020; Parsons and Frank, 2019). We also calculated the percentage of local canopy cover within a $20 \mathrm{~m}$ buffer (excluding open areas and grasslands). We used this buffer size of local canopy cover because the local abundance of trees is a strong driver of urban biodiversity (Herrmann et al., 2012; Long and Frank, 2020; Meyer et al., 2020; Parsons and Frank, 2019; Stemmelen et al., 2020). To that aim we used the High Resolution Layers of the CORINE land cover datasets with $10 \mathrm{~m}$ resolution and with reference year 2018 ( \pm 1 year). Tree Cover Density extracted from the CORINE dataset consists of tree cover density in a range from 0 to $100 \%$, while the urbanization extracted from the CORINE dataset consists of artificially sealed areas (imperviousness ranging from 1 to $100 \%$ ). We assumed that landscape characteristics did not change during the survey period (2018-2020).

To control for variability in herbivory that is influenced by local climatic conditions (Valdés-Correcher et al., 2021), we extracted spring temperature and precipitation (mean temperature and precipitation in AprilJune) data from the WorldClim database (Hijmans et al., 2005) on the basis of the oak coordinates. Spring temperature and precipitation correspond to the period when most of the partners collected the leaves and also the main period of activity of insect herbivores on oak. Urbanization and local canopy cover were slightly negatively correlated (Pearson $\mathrm{r}=-0.38, P<0.05$ ), and were independent of latitude (Urbanization: Pearson $\mathrm{r}=0.02, P>0.05$; Local canopy cover: Pearson $\mathrm{r}=0.04, P>0.05$ ) and climate (Temperature and urbanization: Pearson $\mathrm{r}=-0.02, P>0.05$; Temperature and local canopy cover: Pearson $\mathrm{r}=-0.12, P$ $<0.05$; Precipitation and urbanization: Pearson $\mathrm{r}=0.03, P>0.05$; Precipitation and local canopy cover: Pearson $\mathrm{r}=0.01, P>0.05$ ). Although latitude was negatively correlated with temperature (Pearson $\mathrm{r}=$ $-0.76, P<0.05)$ and precipitation (Pearson $\mathrm{r}=-0.70, P<0.05$ ) which could have caused collinearity issue, a previous study found that climatic variables were better predictors of variation in herbivory and therefore decided to only include climatic variables in the models (Valdés-Correcher et al., 2021).

\section{Statistical analysis}

All analyses were run in the $R$ (R Core Team, 2020) with packagesMuMIn (Bartoń, 2020) and lme4 (Bates et al., 2018). We analysed each of the response variables separately with generalized linear mixed-effects models. We tested the effects of urbanization, local canopy cover and their interaction on leaf damage with Gaussian error distribution and identity link (the results were the same with a beta-distribution and loglink), and on the incidence of leaf-miners and gall-inducers with binomial error distribution and logit-link in separate models. The data was not overdispersed, visual inspection of raw-data did not call for zero-inflated models, the distribution of residuals met model assumptions.

In each model, Urbanization (\%), Local canopy cover (\%), Urbanization $\times$ Local canopy cover, Year (as a factor), Spring temperature $\left({ }^{\circ} \mathrm{C}\right)$ and Spring precipitation $(\mathrm{mm})$ were included as fixed effects; and Partner ID as a random factor to account for the fact that some partners surveyed multiple trees and/or several years.

We analysed the data in the framework of information theory (Burnham and Anderson, 2002). We first built three models, one for each response variable separately (leaf damage, gall-inducer and leaf-miner incidences). We scaled and centred all continuous predictor variables prior to modelling to make their coefficients comparable, and verified that uncontrolled correlations among explanatory variables were unlikely to bias model coefficient parameter estimates (all variance inflation factors [VIF] lower than 2) (Zuur et al., 2009). We then applied a procedure of parsimonious model selection based on the Akaike's Information Criterion corrected for small sample sizes (AICc) and considered every model in a range of 2 units of AICc to the best model as equally likely (Arnold, 2010). We calculated the AIC weight $\left(w_{i}\right)$ - i.e., the probability that a given model is the best model within the set of candidate models - and also the relative variable importance (RVI) as the sum of $w_{i}$ of every model including this variable. When multiple models were competing with the best model (i.e., when several models with $\Delta$ AICc $<2$ ), we implemented a multi-model inference approach, constructing a consensus model that comprised the selected variables from the set of best models. We subsequently averaged their effect sizes over all models in the set of best models, utilizing $w_{i}$ as the weighting parameter (i.e., model averaging). A certain predictor was deemed to have a statistically significant effect on the response variable if its $95 \%$ confidence interval did not bracket zero. 


\section{Results}

Urbanization in a buffer of $200 \mathrm{~m}$ radius was on average $9.72 \pm 0.91 \%( \pm \mathrm{SE}, \mathrm{n}=298$ trees$)$ and ranged from 0 to $70 \%$. Local canopy cover in a buffer of $20 \mathrm{~m}$ radius centered on focal oaks was on average 46.51 $\pm 1.90 \%$ and ranged from 0 to $100 \%$ cover.

Leaf damage was on average $7.72 \pm 0.33 \%$. Model selection retained the percentage of urbanization and local canopy cover, year and spring precipitation as important predictors explaining variability in leaf damage (Figure 2A, Table A ). Specifically, leaf damage significantly decreased with increasing urbanization (from 8.23 to $5.59 \%$ along the range of urbanization, Figure BA ) and increased with local canopy cover (from 7.16 to $8.71 \%$ along the range of local canopy cover, Figure BD ). Leaf damage varied across years and was significantly greater in 2019 and lower in 2020 as compared to 2018 (Figure 2A ). Leaf damage decreased significantly with increasing spring precipitation (Figure 2A ). 
A

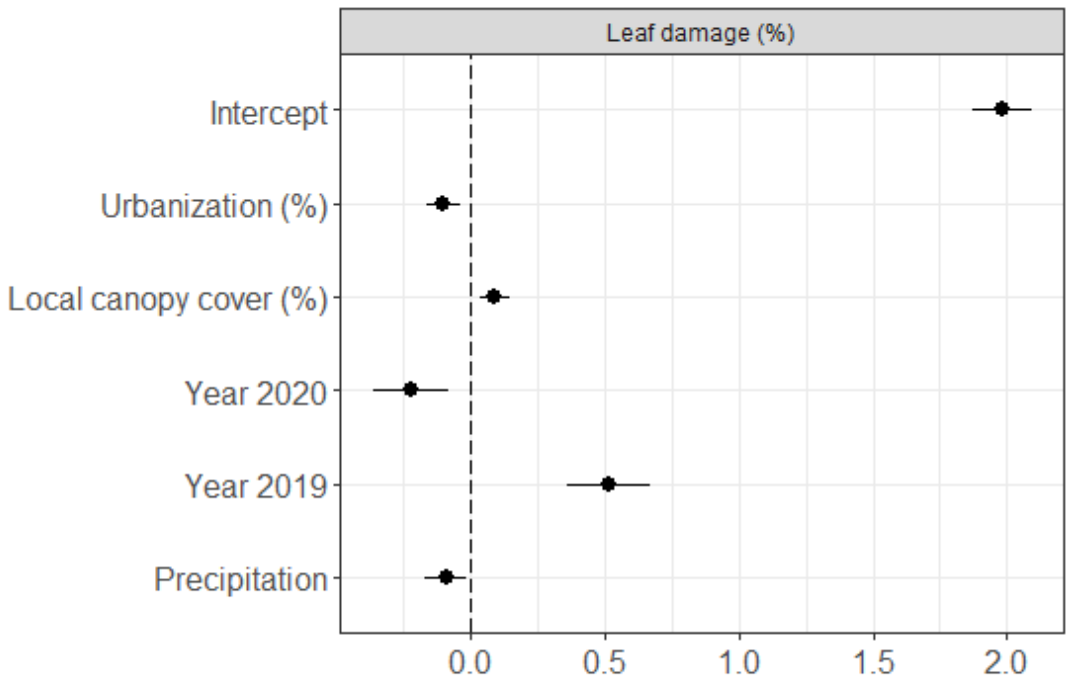

B

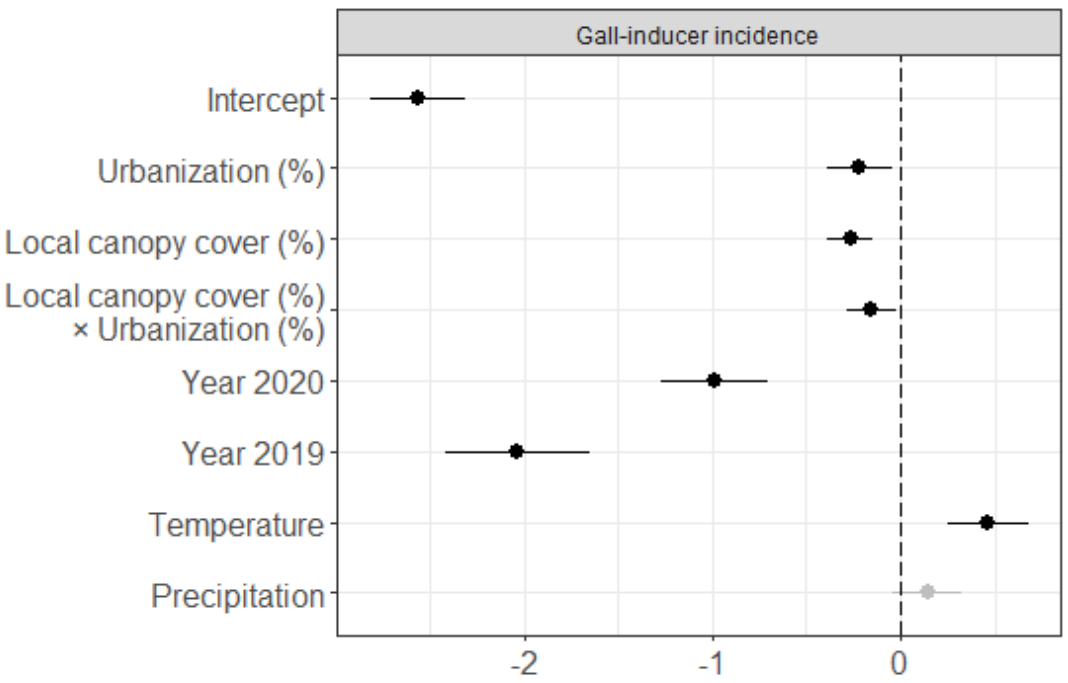

C

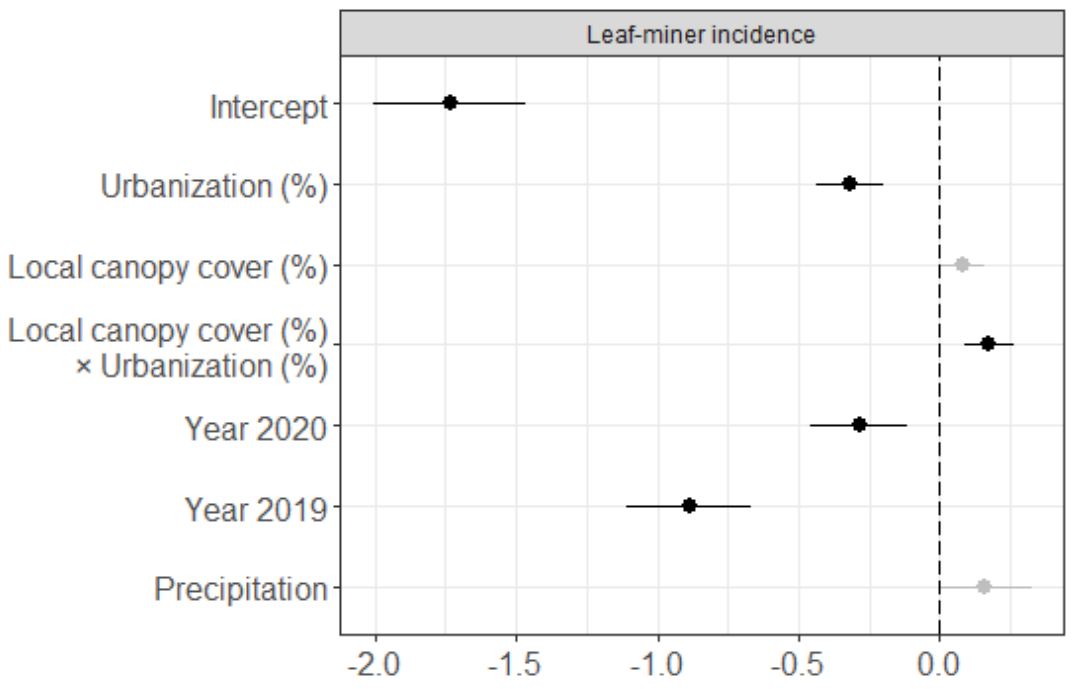

Standardized parameler estimate $\pm 95 \% \mathrm{Cl}$ 
Figure 2. Standardized parameter estimates averaged across the best competing models testing the effects of percentage of urbanization and local canopy cover, their interaction, year, mean spring temperature and/or mean spring precipitation $(\mathrm{n}=298)$ on leaf damage $(\mathrm{A})$ and the incidence of gall-inducing $(\mathrm{B})$ and leafmining $(\mathrm{C})$ herbivores. Circles and error bars represent standardized parameter estimates and corresponding 95\% CI. The vertical dashed line centered on zero indicate the null hypothesis. Black and grey circles indicate significant and non-significant effect sizes, respectively. The year 2018 is the intercept and was contrasted with the years 2019 and 2020.

Insect galls were present on $6.34 \pm 0.01 \%$ of the inspected leaves. Model selection retained the percentage of urbanization and local canopy cover, their interaction, year, spring temperature, and spring precipitation as important predictors explaining variability in leaf-gall incidence (Figure 2B, Table A ). In particular, gall-inducer incidence significantly decreased with increasing urbanization (from 6.30 to $5.00 \%$ along the urbanization range,Figure 2B, Figure BB ) and with increasing local canopy cover (from 8.00 to $0.06 \%$ along the range of local canopy cover,Figure 2B, Figure BE ). The effect of urbanization on gall-inducer incidence was, however, contingent on local canopy cover (significant urbanization $\times$ local canopy cover interaction;Figure 2B, Figure 3A ): the negative effect of urbanization on gall-inducer incidence was more pronounced when there was a greater canopy cover around focal oaks. The incidence of gall-inducers was significantly lower in 2019 and 2020 as compared to 2018, and significantly increased with increasing spring temperature (Figure 2B ). Spring precipitation had no consistent effect on gall-inducer incidence (Figure 2B ).
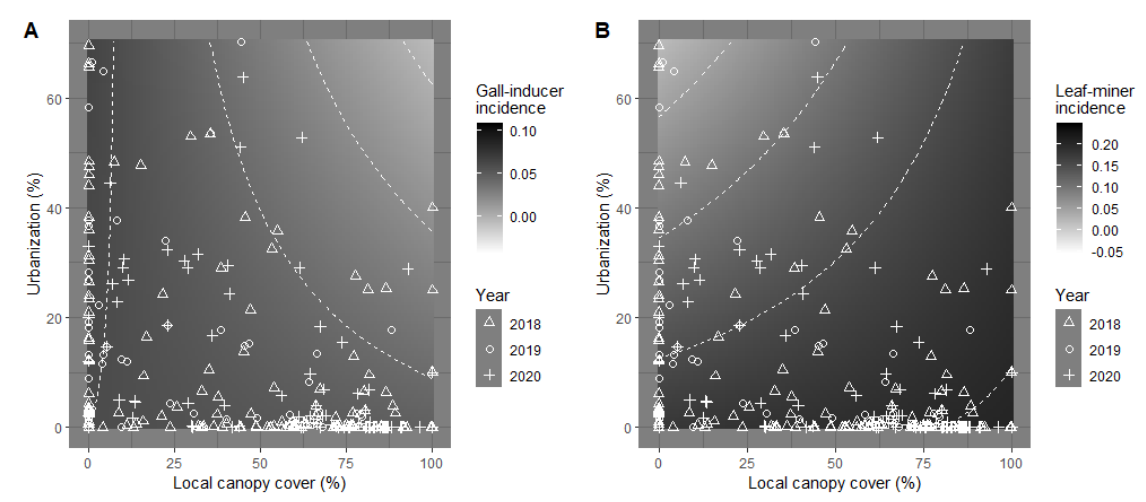

Figure 3 . Interactive effect of percentage of urbanization and of local canopy cover (measured as the cover of urban and local canopy cover within a buffer of 200 and $20 \mathrm{~m}$ radius, respectively) on the incidence of gall-inducing (A) and leaf-mining herbivores (B).

Leaf miners were present in $17.98 \pm 0.01 \%$ of the sampled leaves. Model selection retained the percentage of urbanization, local canopy cover, their interaction, year and spring precipitation as important predictors explaining variability in leaf-miner incidence (Figure 2C, Table A ). Specifically, leaf-miner incidence significantly decreased with increasing urbanization (from 21.33 to $1.00 \%$ along the range of urbanization, Figure 2C, Figure B ). The effect of urbanization on leaf-miner incidence was, however, contingent on local canopy cover (significant urbanization $\times$ local canopy cover interaction;Figure 2C, Figure 3B ): the negative effect of urbanization on leaf-miner incidence was more pronounced when there was a lower canopy cover around focal oaks. It was significantly lower in 2019 and 2020 as compared to 2018 (Figure 2C ). Spring precipitation and local canopy cover had no consistent effect on leaf-miner incidence (Figure 2C , Figure B ).

\section{Discussion}

Our study revealed that urbanization can consistently reduce insect herbivory on the pedunculate oak throughout its geographic range. The effect of urbanization was partially modulated by the percentage of canopy 
cover around oaks, with differences among herbivore feeding guilds. Specifically, we found that urbanization and local canopy cover had independent and opposite effects on overall leaf damage. In contrast, effects of urbanization on gall-inducer and leaf-miner incidence depended on local canopy cover, with a more pronounced negative effect of urbanization on gall-inducer and leaf-miner incidence when there was a greater and lower local canopy cover, respectively. These results show the complexity of plant-herbivore interactions in urbanized areas, highlighting that local habitat characteristics within cities have the potential to attenuate or modify the effect of urbanization on biotic interactions.

\section{Effect of urbanization on herbivory}

We found that the incidence of both gall-inducing and leaf-mining herbivores decreased with increasing urbanization, suggesting that the abundance of these species decreased with urbanization. This result agrees with previous reports that have shown that urbanization reduces the abundance and diversity of several guilds of insect herbivores (Barr et al., 2021; Dobrosavljević et al., 2020; Fenoglio et al., 2020; Herrmann et al., 2012; Kozlov et al., 2017; Moreira et al., 2019) with the noticeable exception of sap-feeding herbivores (de Andrade and Rivkin, 2020; Parsons and Frank, 2019). For instance, Herrmann et al. (2012) found lower species richness of galler communities on the valley oak (Quercus lobata) in urban areas than in natural areas. Similarly, Dobrosavljević et al. (2020) found lower richness, abundance and diversity of leaf-miner communities on the pedunculate oak in urban areas than in natural areas.

We also found that leaf damage decreased with increasing urbanization around focal oaks. Although this result aligns with the observation that the incidence of gall-inducing and leaf-mining herbivores decreased with increasing urbanization, it is important to consider that leaf damage (i.e., the amount of biomass consumed by chewing herbivores) may not scale proportionally with the abundance and diversity of insect herbivores. Several other ecological factors that are influenced by urbanization may determine the amount of damage caused by chewing herbivores. They include the top-down control of herbivore populations by their enemies (Kozlov et al., 2017; Planillo et al., 2021; Turrini et al., 2016) as well as plant defenses and quality (Moreira et al., 2019; Thompson et al., 2016). The correlative nature of our data does not allow further robust inferences on the mechanisms underlying the observed patterns.

\section{Effect of local canopy cover on herbivory}

Herbivory varied with canopy cover in the immediate vicinity of oaks, but this effect was guild specific: there was an independent positive effect of local canopy cover on herbivory, a negative effect on gall-inducing herbivores, and no effect on leaf-mining herbivores. Whereas several studies have compared herbivore abundance or diversity, and sometimes herbivory, between urban and forested environments (Herrmann et al., 2012; Kozlov et al., 2017; Moreira et al., 2019), only a handful of them have addressed the effect of urban tree density on insect herbivores (Barr et al., 2021; Christie et al., 2010; Christie and Hochuli, 2005; Herrmann et al., 2012; Long and Frank, 2020; Meyer et al., 2020; Raupp et al., 2010). Their findings were contradictory with reports of both higher (Christie and Hochuli, 2005) and lower (Herrmann et al., 2012; Long and Frank, 2020) herbivory in isolated trees as compared to trees growing in larger forest patches. This effect of local canopy cover also mirrors variability in the response of herbivory to the size of forest fragments (De La Vega et al., 2012; Kaartinen and Roslin, 2011; Simonetti et al., 2007; Valdés-Correcher et al., 2019). We therefore refrain from putting forth any particular mechanism that may underlay the patterns we observed. However, we speculate that denser tree canopies may have buffered micro-climatic variations (Coley and Barone, 1996; Dale and Frank, 2014; Yamasaki and Kikuzawa, 2003), which may have been particularly favourable to chewing herbivores that are external feeders (Savilaakso et al., 2009) and at the same time unfavorable to leaf-galling herbivores, as they benefit from high temperatures (Valdés-Correcher et al., 2021). Alternatively, top-down forces also vary with local canopy cover and may consequently influence insect herbivory. For instance, predation activity of birds (Stemmelen et al., 2020) and the abundance of birds (Valdés-Correcher et al., 2019) increase with increasing local canopy cover. However, if the observed negative association between herbivory and forest cover would have been mediated by bird predation, it would have displayed the opposite pattern. Deciphering the relative importance of the mechanisms acting upon insect herbivores will represent a major step forward in our understanding of insect herbivory in urban environments. 


\section{Interactive effect of urbanization and local canopy cover on herbivory}

Cities are heterogeneous environments where greenness may vary widely. The design of our study allowed us to partially disentangle the response of herbivory to the joint variation in urbanization and local canopy cover. We found that increasing local canopy cover modulated the effect of urbanization on some herbivores. Specifically, the negative effect of urbanization on gall-inducing herbivores strengthened with increasing local canopy cover, whereas increasing local canopy cover annulled the effect of urbanization on leaf-mining herbivores. Urbanization and local canopy cover have antagonistic effects on the microclimate and enemy pressure. Cities are warmer than the surrounding rural areas as a result of the "heat island effect" (Kalnay and Cai, 2003; Parker, 2010; Roth et al., 1989), which is buffered by the presence of trees (Loughner et al., 2012; Nuruzzaman, 2015). Likewise, forest patches in urban environments serve as habitats for both herbivores and predators, which is likely to modify the strength of horizontal (herbivores-herbivores) and vertical (herbivorespredators) interactions in urban trees (Long et al., 2019; Long and Frank, 2020). Endophagous herbivores such as gall-inducers and leaf-miners are more sheltered from the environment than ectophagous herbivores. Thus, ectophagous herbivores may be more sensitive to local environmental conditions than endophagous herbivores. For instance, we found a positive relationship between the incidence of gall-inducing herbivores and temperature. It is possible that by buffering the heat island effect, the presence of a denser canopy reduced the incidence of gall-inducers on oaks. On the contrary, leaf-mining herbivores were found to be favoured by lower (Gaston et al., 2004) or intermediate temperatures (Valdés-Correcher et al., 2021). For these herbivores, a denser canopy could have negated the heat island effects, creating more favourable habitats. We cannot exclude that the interactive effect of urbanization and canopy cover was partially dependent on differential predation rates, but this could not be investigated in the present study.

\section{Effect of climate on insect herbivory}

Climatic variables were included in the analyses to take into account that oaks were sampled along a latitudinal gradient. They had a significant effect on insect herbivory and this effect varied among feeding guilds. Consistently with previous studies (Kozlov et al., 2016; Valdés-Correcher et al., 2021), we found that precipitation had a negative effect on leaf damage; temperature had a positive effect on gall-inducer incidence, whereas leaf-miner incidence did not vary with climate. The differences in the effect of climate among feeding guilds may be due to differences in insect herbivore strategies to survive different climatic conditions, which was discussed extensively in a previous paper (see Valdés-Correcher et al., 2021).

\section{Conclusions}

Our simultaneous consideration of the effect of urbanization and local canopy cover on insect herbivory provides novel insights into plant-herbivore interactions. We found that insect herbivory responds simultaneously to both urbanization and local canopy cover in the pedunculate oak in the major part of its geographic range. Importantly, our results highlight that urbanization has a negative effect on insect herbivory across the three feeding guilds. However, local canopy cover as well as its interaction with urbanization influenced insect herbivory of different feeding guilds differently. Thus, local canopy cover within cities has the capacity to mitigate or modify the effect of urbanization on biotic interactions, as it influences the effect of urbanization on herbivores differently. Therefore, this study supports the importance of maintaining trees in urban areas as it may consequently contribute to the preservation of biodiversity of insect herbivores in urban areas. Important insights will be gained by investigating the mechanisms driving these patterns, in particular by deciphering the interactive effects of urbanization and canopy cover on the microclimate and enemy pressures herbivores are exposed to.

\section{Acknowledgments}

This study was carried out with financial support from the French National Research Agency (ANR) in the frame of the Investments for the Future Programme, within the Cluster of Excellence COTE (Continental To coastal Ecosystems: evolution, adaptability and governance) (ANR-10-LABX-45) and was further funded by the BNP Paribas Foundation as part of its Climate \& Biodiversity Initiative the citizen science project Tree Bodyguards. 
The authors warmly thank all the young European citizens and their teachers who made this study possible. They also thank the professional scientists who kindly agreed to participate in this study: Alexander Kozel (Belarusian State Technological University and American Psychological Association), Andreas Schuldt (Forest Nature Conservation, Georg-August-University Göttingen, Göttingen, German), Aurélien Sallé (Laboratoire de Biologie des Ligneux et des Grandes Cultures, INRAE, Université d'Orléans), Chloe Mendiondo and Claire Colliaux (Department of Agroecology, Aarhus University, Flakkebjerg Research Centre, DK-4200 Slagelse, Denmark), György Csóka (Department of Forest Protection, NARIC Forest Research Institute, Mátrafüred, Hungary), Lars Opgennoorth (Biodiversity and Conservation Biology, Ecological Genetics, Swiss Federal Research Institute WSL, Birmensdorf, Switzerland), Laurent Augusto (INRAE, Bordeaux Sciences Agro), Marija Popović (Faculty of Forestry, University of Belgrade, Belgrade, Serbia), Mickael Pihain (Research Unit "Ecosystèmes, Biodiversité, Evolution", University of Rennes 1/CNRS, 35042 Rennes, France), Olivier Bouriaud (Applied Ecology Laboratory, Forestry Faculty, "Ștefan cel Mare, University of Suceava, Suceava, Romania), Stefan K. Müller (Freie evangelische Schule Lörrach), Tomas Roslin (Department of Ecology; Swedish University of Agricultural Sciences), Valentin Queloz (Forest Entomology, Swiss Federal Research Institute WSL) and Vojtech Lanta (Institute of Botany CAS, Dukelská 135, 37901 Třeboň, Czech Republic). They also thank Michael Scherer-Lorenzen (Geobotany, Faculty of Biology, University of Freiburg) for the help during the coordination of the research.

\section{Author contributions}

EVC and BC designed the study, analysed the data and led the writing. EVC and BC coordinated the research, with help from DH, MB, MMG and RT. AG, AGH, AMD, A. Prinzing, CB, DH, DLM, GL, IVH, JD, JH, JK, KS, LB, M. Branco, MC, MCB, M. Bogdziewicz, M. Ferrante, MMG, MVK, PFC, RLT, RW, SG and XM collected data and gave critical comments on the manuscript; and AM, AP, AVS, DL, GC, JMP, M. Faticov, MLD, MT, NAM, SM and YK contributed data.

\section{Data accessibility statement}

We declare that after acceptance of our manuscript we will archive our data in a publicly accessible repository such as Dryad.

\section{References}

Arnold, T.W., 2010. Uninformative Parameters and Model Selection Using Akaike's Information Criterion. J. Wildl. Manage. 74, 1175-1178. https://doi.org/10.2193/2009-367

Bang, C., Faeth, S.H., 2011. Variation in arthropod communities in response to urbanization: Seven years of arthropod monitoring in a desert city. Landsc. Urban Plan. 103, 383-399. https://doi.org/10.1016/j.landurbplan.2011.08.013

Barr, A.E., van Dijk, L.J.A., Hylander, K., Tack, A.J.M., 2021. Local habitat factors and spatial connectivity jointly shape an urban insect community. Landsc. Urban Plan. 214. https://doi.org/10.1016/j.landurbplan.2021.104177

Bartoń, K., 2020. MuMIn: Multi-Model Inference. R package version 1.43. 17.

Bates, D., Maechler, M., Bolker, B., Walker, S., 2018. Ime4: Linear Mixed-Effects Models using "Eigen" and S4.

Burnham, K.P., Anderson, D.R., 2002. Model selection and multimodel interference, a practical informationTheoretic approach. 2nd ed. Springer, New York, 2. https://doi.org/10.1017/CBO9781107415324.004

Calfapietra, C., Peñuelas, J., Niinemets, Ü., 2015. Urban plant physiology: Adaptation-mitigation strategies under permanent stress. Trends Plant Sci. 20, 72-75. https://doi.org/10.1016/j.tplants.2014.11.001

Castagneyrol, B., Valdés-Correcher, E., Kaennel Dobbertin, M., Gossner, M.M., 2019. Predation assessment on fake caterpillars and leaf sampling: Protocol for partner schools. protocols.io. https://doi.org/DOI: https://doi.org/10.17504/protocols.io.42pgydn. 
Chai, L., Huang, M., Fan, H., Wang, J., Jiang, D., Zhang, M., Huang, Y., 2019. Urbanization altered regional soil organic matter quantity and quality: Insight from excitation emission matrix (EEM) and parallel factor analysis (PARAFAC). Chemosphere 220, 249-258. https://doi.org/10.1016/j.chemosphere.2018.12.132

Chávez-Pesqueira, M., Carmona, D., Suárez-Montes, P., Núñez-Farfán, J., Aguilar, R., 2015. Synthesizing habitat fragmentation effects on plant-antagonist interactions in a phylogenetic context. Biol. Conserv. 192, 304-314. https://doi.org/10.1016/j.biocon.2015.10.002

Christie, F.J., Cassis, G., Hochuli, D.F., 2010. Urbanization affects the trophic structure of arboreal arthropod communities. Urban Ecosyst. 13, 169-180. https://doi.org/10.1007/s11252-009-0115-x

Christie, F.J., Hochuli, D.F., 2005. Elevated levels of herbivory in urban landscapes: Are declines in tree health more than an edge effect? Ecol. Soc. 10. https://doi.org/10.5751/ES-00704-100110

Coley, P.., Barone, J.., 1996. Herbivory and plant defenses in tropical forests. Annu. Rev. Ecol. Syst. 27, 305-335.

Cuevas-Reyes, P., Gilberti, L., González-Rodríguez, A., Fernandes, G.W., 2013. Patterns of herbivory and fluctuating asymmetry in Solanum lycocarpum St. Hill (Solanaceae) along an urban gradient in Brazil. Ecol. Indic. 24, 557-561. https://doi.org/10.1016/j.ecolind.2012.08.011

Dale, A.G., Frank, S.D., 2014. Urban warming trumps natural enemy regulation of herbivorous pests. Ecol. Appl. 24, 1596-1607. https://doi.org/10.1890/13-1961.1

de Andrade, A.C., Rivkin, L.R., 2020. Road to ruin: Herbivory in a common tropical weed (Turnera subulata ) along a rural-urban gradient. bioRxiv 1-15. https://doi.org/10.1101/2020.09.26.314765

De La Vega, X., Grez, A.A., Simonetti, J.A., 2012. Is top-down control by predators driving insect abundance and herbivory rates in fragmented forests? Austral Ecol. 37, 836-844. https://doi.org/10.1111/j.14429993.2011.02345.x

DeMars, C.A., Rosenberg, D.K., Fontaine, J.B., 2010. Multi-scale factors affecting bird use of isolated remnant oak trees in agro-ecosystems. Biol. Conserv. 143, 1485-1492. https://doi.org/10.1016/j.biocon.2010.03.029

Dobrosavljević, J., Marković, Č., Marjanović, M., Milanović, S., 2020. Pedunculate oak leaf miners' community: Urban vs. rural habitat. Forests 11, 1-15. https://doi.org/10.3390/f11121300

Dreistadt, S.H., Dahlsten, D.L., Frankie, G.W., 1990. Urban Forests and Insect Ecology. Bioscience 40, 192-198. https://doi.org/10.2307/1311364

Eaton, E., Caudullo, G., Oliveira, S., de Rigo, D., 2016. Quercus robur and Quercus petraea. Eur. Atlas For. Tree Species 160-163. https://doi.org/10.2788/038466

Fenoglio, M.S., Rossetti, M.R., Videla, M., 2020. Negative effects of urbanization on terrestrial arthropod communities: A meta-analysis. Glob. Ecol. Biogeogr. 29, 1412-1429. https://doi.org/10.1111/geb.13107

Fischer, J., Stott, J., Law, B.S., 2010. The disproportionate value of scattered trees. Biol. Conserv. 143, 1564-1567. https://doi.org/10.1016/j.biocon.2010.03.030

Gaston, K.J., Genney, D.R., Thurlow, M., Hartley, S.E., 2004. The geographical range structure of the holly leaf-miner. IV. Effects of variation in host-plant quality. J. Anim. Ecol. 73, 911-924. https://doi.org/10.1111/j.0021-8790.2004.00866.x

Herrmann, D.L., Pearse, I.S., Baty, J.H., 2012. Drivers of specialist herbivore diversity across 10 cities. Landsc. Urban Plan. 108, 123-130. https://doi.org/10.1016/j.landurbplan.2012.08.007

Hijmans, R.J., Cameron, S.E., Parra, J.L., Jones, P.G., Jarvis, A., 2005. Very high resolution interpolated climate surfaces for global land areas. Int. J. Climatol. 25, 1965-1978. https://doi.org/10.1002/joc.1276 
James Barth, B., Ian FitzGibbon, S., Stuart Wilson, R., 2015. New urban developments that retain more remnant trees have greater bird diversity. Landsc. Urban Plan. 136, 122-129. https://doi.org/10.1016/j.landurbplan.2014.11.003

Jamieson, M.A., Trowbridge, A.M., Raffa, K.F., Lindroth, R.L., 2012. Consequences of climate warming and altered precipitation patterns for plant-insect and multitrophic interactions. Plant Physiol. 160, 1719-1727. https://doi.org/10.1104/pp.112.206524

Kaartinen, R., Roslin, T., 2011. Shrinking by numbers: Landscape context affects the species composition but not the quantitative structure of local food webs. J. Anim. Ecol. 80, 622-631. https://doi.org/10.1111/j.1365-2656.2011.01811.x

Kalnay, E., Cai, M., 2003. Impact of urbanization and land-use. Nature 425, 102-102. https://doi.org/10.1038/nature01649.1.

Koricheva, J., Larsson, S., Haukioja, E., 1998. Insect performance on experimentally stressed woody plants: A meta-analysis. Annu. Rev. Entomol. 43, 195-216. https://doi.org/10.1146/annurev.ento.43.1.195

Kozlov, M. V., Lanta, V., Zverev, V., Rainio, K., Kunavin, M.A., Zvereva, E.L., 2017. Decreased losses of woody plant foliage to insects in large urban areas are explained by bird predation. Glob. Chang. Biol. 23, 4354-4364. https://doi.org/10.1111/gcb.13692

Kozlov, M. V., Lanta, V., Zverev, V., Zvereva, E.L., 2015. Global patterns in background losses of woody plant foliage to insects. Glob. Ecol. Biogeogr. 24, 1126-1135. https://doi.org/10.1111/geb.12347

Kozlov, M. V., Skoracka, A., Zverev, V., Lewandowski, M., Zvereva, E.L., 2016. Two birch species demonstrate opposite latitudinal patterns in infestation by gall-making mites in northern Europe. PLoS One 11, 1-15. https://doi.org/10.1371/journal.pone.0166641

Lambert, M.R., Giller, G.S.J., Barber, L.B., Fitzgerald, K.C., Skelly, D.K., 2015. Suburbanization, estrogen contamination, and sex ratio in wild amphibian populations. Proc. Natl. Acad. Sci. U. S. A. 112, 1188111886. https://doi.org/10.1073/pnas. 1501065112

Le Roux, D.S., Ikin, K., Lindenmayer, D.B., Manning, A.D., Gibbons, P., 2018. The value of scattered trees for wildlife: Contrasting effects of landscape context and tree size. Divers. Distrib. 24, 69-81. https://doi.org/10.1111/ddi.12658

Long, L.C., D'Amico, V., Frank, S.D., 2019. Urban forest fragments buffer trees from warming and pests. Sci. Total Environ. 658, 1523-1530. https://doi.org/10.1016/j.scitotenv.2018.12.293

Long, L.C., Frank, S.D., 2020. Risk of bird predation and defoliating insect abundance are greater in urban forest fragments than street trees. Urban Ecosyst. 23, 519-531. https://doi.org/10.1007/s11252-020-00939-x

Loughner, C.P., Allen, D.J., Zhang, D.L., Pickering, K.E., Dickerson, R.R., Landry, L., 2012. Roles of urban tree canopy and buildings in urban heat island effects: Parameterization and preliminary results. J. Appl. Meteorol. Climatol. 51, 1775-1793. https://doi.org/10.1175/JAMC-D-11-0228.1

Magura, T., Lövei, G.L., Tóthmérész, B., 2010. Does urbanization decrease diversity in ground beetle (Carabidae) assemblages? Glob. Ecol. Biogeogr. 19, 16-26. https://doi.org/10.1111/j.1466-8238.2009.00499.x

Marković, C., Stojanović, A., 2011. Phloemophagous and xylophagous insects, their parasitoids, predators and inquilines in the branches of the most important oak species in Serbia. Biologia (Bratisl). 66, 509-517.

McDonnell, M.J., Hahs, A.K., 2015. Adaptation and Adaptedness of Organisms to Urban Environments. Annu. Rev. Ecol. Evol. Syst. 46, 261-280. https://doi.org/10.1146/annurev-ecolsys-112414-054258

Meineke, E.K., Frank, S.D., 2018. Water availability drives urban tree growth responses to herbivory and warming. J. Appl. Ecol. 55, 1701-1713. https://doi.org/10.1111/1365-2664.13130 
Meyer, S., Rusterholz, H.P., Baur, B., 2020. Urbanisation and forest size affect the infestation rates of plant-galling arthropods and damage by herbivorous insects. Eur. J. Entomol. 117, 34-48. https://doi.org/10.14411/EJE.2020.004

Moreira, X., Abdala-Roberts, L., Berny Mier y Teran, J.C., Covelo, F., de la Mata, R., Francisco, M., Hardwick, B., Pires, R.M., Roslin, T., Schigel, D.S., ten Hoopen, J.P.J.G., Timmermans, B.G.H., van Dijk, L.J.A., Castagneyrol, B., Tack, A.J.M., 2019. Impacts of urbanization on insect herbivory and plant defences in oak trees. Oikos 128, 113-123. https://doi.org/10.1111/oik.05497

Moreira, X., Abdala-Roberts, L., Berny Mier y Teran, J.C., Covelo, F., de la Mata, R., Francisco, M., Hardwick, B., Pires, R.M., Roslin, T., Schigel, D.S., ten Hoopen, J.P.J.G., Timmermans, B.G.H., van Dijk, L.J.A., Castagneyrol, B., Tack, A.J.M., 2018. Impacts of urbanization on insect herbivory and plant defences in oak trees. Oikos 128, 113-123. https://doi.org/10.1111/oik.05497

Nuruzzaman, M., 2015. Urban heat island: causes, effects and mitigation measures. Int. J. Environ. Monit. Anal. 3, 67. https://doi.org/10.11648/j.ijema.20150302.15

Parker, D.E., 2010. Urban heat island effects on estimates of observed climate change. Wiley Interdiscip. Rev. Clim. Chang. 1, 123-133. https://doi.org/10.1002/wcc.21

Parsons, S.E., Frank, S.D., 2019. Urban tree pests and natural enemies respond to habitat at different spatial scales. J. Urban Ecol. 5, 1-15. https://doi.org/10.1093/jue/juz010

Pickett, S.T.A., Cadenasso, M.L., Grove, J.M., Nilon, C.H., Pouyat, R. V., Zipperer, W.C., Costanza, R., 2001. Urban ecological systems: Linking terrestrial ecological, physical, and socioeconomic components of metropolitan areas. Annu. Rev. Ecol. Syst. 32, 127-157. https://doi.org/10.1007/978-0-387-73412-5_7

Planillo, A., Kramer-Schadt, S., Buchholz, S., Gras, P., von der Lippe, M., Radchuk, V., 2021. Arthropod abundance modulates bird community responses to urbanization. Divers. Distrib. 27, 34-49. https://doi.org/10.1111/ddi.13169

R Core Team, 2020. R: A Language and environment for statistical computing.

Raupp, M.J., Shrewsbury, P.M., Herms, D.A., 2010. Ecology of herbivorous arthropods in urban landscapes. Annu. Rev. Entomol. 55, 19-38. https://doi.org/10.1146/annurev-ento-112408-085351

Rossetti, M.R., Tscharntke, T., Aguilar, R., Batáry, P., 2017. Responses of insect herbivores and herbivory to habitat fragmentation: a hierarchical meta-analysis. Ecol. Lett. 20, 264-272. https://doi.org/10.1111/ele.12723

Roth, M., Oke, T.R., Emery, W.J., 1989. Satellite-derived urban heat islands from three coastal cities and the utilization of such data in urban climatology. Int. J. Remote Sens. 10.11.

Savilaakso, S., Koivisto, J., Veteli, T.O., Roininen, H., 2009. Microclimate and tree community linked to differences in lepidopteran larval communities between forest fragments and continuous forest. Divers. Distrib. 15, 356-365. https://doi.org/10.1111/j.1472-4642.2008.00542.x

Schaefer, C.W., Panizzi, A.R., 2000. Heteroptera of Economic Importance, CRC Press. ed.

Shrewsbury, P.M., Raupp, M.J., 2000. Evaluation of components of vegetational texture for predicting azalea lace bug, Stephanitis pyrioides (Heteroptera: Tingidae), abundance in managed landscapes. Environ. Entomol. 29, 919-926. https://doi.org/10.1603/0046-225X-29.5.919

Simonetti, J.A., Grez, A.A., Celis-Diez, J.L., Bustamante, R.O., 2007. Herbivory and seedling performance in a fragmented temperate forest of Chile. Acta Oecologica 32, 312-318. https://doi.org/10.1016/j.actao.2007.06.001

Southwood, T.R.E., Wint, W.G.R., Kennedy, C.E.J., Greenwood, S.R., 2005. Composition of arthropod fauna in some species of Quercus . Eur. J. Entomol. 102, 65-72. 
Stam, J.M., Kroes, A., Li, Y., Gols, R., Van Loon, J.J.A., Poelman, E.H., Dicke, M., 2014. Plant interactions with multiple insect herbivores: From community to genes. Annu. Rev. Plant Biol. 65, 689-713. https://doi.org/10.1146/annurev-arplant-050213-035937

Stemmelen, A., Paquette, A., Benot, M.L., Kadiri, Y., Jactel, H., Castagneyrol, B., 2020. Insect herbivory on urban trees: Complementary effects of tree neighbours and predation. bioRxiv 1-16. https://doi.org/10.1101/2020.04.15.042317

Taha, H., 1997. Urban climates and heat islands: Albedo, evapotranspiration, and anthropogenic heat. Energy Build. 25, 99-103. https://doi.org/10.1016/s0378-7788(96)00999-1

Thompson, K.A., Renaudin, M., Johnson, M.T.J., 2016. Urbanization drives the evolution of parallel clines in plant populations. Proc. R. Soc. B Biol. Sci. 283. https://doi.org/10.1098/rspb.2016.2180

Turrini, T., Sanders, D., Knop, E., 2016. Effects of urbanization on direct and indirect interactions in a tri-trophic system. Ecol. Appl. 26, 664-675.

Valdés-Correcher, E., Moreira, X., Augusto, L., Barbaro, L., Bouget, C., Bouriaud, O., Branco, M., Centenaro, G., Csóka, G., Damestoy, T., Dobrosavljević, J., Duduman, M.L., Dulaurent, A.M., Eötvös, C.B., Faticov, M., Ferrante, M., Fürjes-Mikó, Á., Galmán, A., Gossner, M.M., Hampe, A., Harvey, D., Gordon Howe, A., Kadiri, Y., Kaennel-Dobbertin, M., Koricheva, J., Kozel, A., Kozlov, M. V., Lövei, G.L., Lupaștean, D., Milanović, S., Mrazova, A., Opgennoorth, L., Pitkänen, J.M., Popova, A., Popović, M., Prinzing, A., Queloz, V., Roslin, T., Sallé, A., Sam, K., Scherer-Lorenzen, M., Schuldt, A., Selikhovkin, A., Suominen, L., Tack, A.J.M., Tahadlova, M., Thomas, R., Castagneyrol, B., 2021. Search for top-down and bottom-up drivers of latitudinal trends in insect herbivory in oak trees in Europe. Glob. Ecol. Biogeogr. 30, 651-665. https://doi.org/10.1111/geb.13244

Valdés-Correcher, E., van Halder, I., Barbaro, L., Castagneyrol, B., Hampe, A., 2019. Insect herbivory and avian insectivory in novel native oak forests: Divergent effects of stand size and connectivity. For. Ecol. Manage. 445, 146-153. https://doi.org/10.1016/j.foreco.2019.05.018

Van Der Putten, W.H., Macel, M., Visser, M.E., 2010. Predicting species distribution and abundance responses to climate change: Why it is essential to include biotic interactions across trophic levels. Philos. Trans. R. Soc. B Biol. Sci. 365, 2025-2034. https://doi.org/10.1098/rstb.2010.0037

Wang, H., Marshall, C.W., Cheng, M., Xu, H., Li, H., Yang, X., Zheng, T., 2017. Changes in land use driven by urbanization impact nitrogen cycling and the microbial community composition in soils. Sci. Rep. 7, 1-12. https://doi.org/10.1038/srep44049

Yamasaki, M., Kikuzawa, K., 2003. Temporal and spatial variations in leaf herbivory within a canopy of Fagus crenata . Oecologia 137, 226-232. https://doi.org/10.1007/s00442-003-1337-x

Zipperer, W.C., Wu, J., Pouyat, R. V., Pickett, S.T., 2000. The application of ecological principles to urban and urbanizing landscapes. Ecol. Appl. 10, 685-688. https://doi.org/10.1890/10510761(2000)010[0676:SRFNAE]2.0.CO;2

Zuur, A.F., Ieno, E.N., Walker, N.J., Saveliev, A.A., Smith, G.M., 2009. Mixed Effects Models and Extensions in Ecology with R, Springer. ed. New York.

\section{Hosted file}

List of figures.docx available at https://authorea.com/users/444427/articles/544167herbivory-on-the-pedunculate-oak-along-urbanization-range-in-europe-effects-of-localforest-cover-and-insect-feeding-guild 